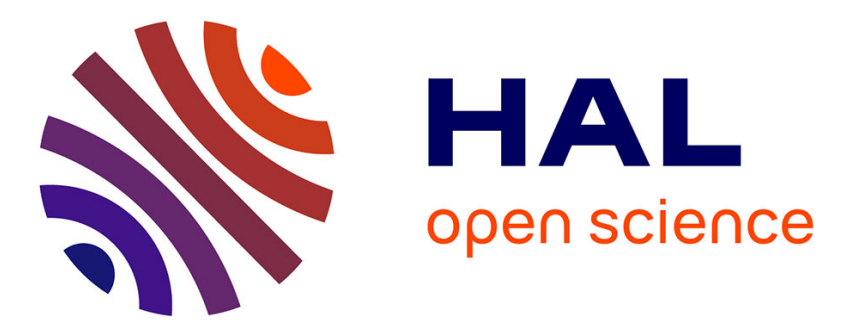

\title{
Development of Ultraviolet-Ultraviolet Hole-Burning Spectroscopy for Cold Gas-Phase Ions
}

Géraldine Féraud, Claude Dedonder, Christophe Jouvet, Yoshiya Inokuchi, Takeharu Haino, Ryo Sekiya, Takayuki Ebata

\section{- To cite this version:}

Géraldine Féraud, Claude Dedonder, Christophe Jouvet, Yoshiya Inokuchi, Takeharu Haino, et al.. Development of Ultraviolet-Ultraviolet Hole-Burning Spectroscopy for Cold Gas-Phase Ions. Journal of Physical Chemistry Letters, 2014, 5 (7), pp.1236-1240. 10.1021/jz500478w . hal-01009690

\section{HAL Id: hal-01009690 \\ https://hal.science/hal-01009690}

Submitted on 8 Dec 2017

HAL is a multi-disciplinary open access archive for the deposit and dissemination of scientific research documents, whether they are published or not. The documents may come from teaching and research institutions in France or abroad, or from public or private research centers.
L'archive ouverte pluridisciplinaire HAL, est destinée au dépôt et à la diffusion de documents scientifiques de niveau recherche, publiés ou non, émanant des établissements d'enseignement et de recherche français ou étrangers, des laboratoires publics ou privés. 


\section{Development of Ultraviolet-Ultraviolet Hole-burning Spectroscopy for Cold Gas Phase Ions}

Géraldine Féraud ${ }^{1}$, Claude Dedonder ${ }^{1}$, Christophe Jouvet $^{1 *}$, Yoshiya Inokuchi ${ }^{2}$, Takeharu Haino ${ }^{2}$, Ryo Sekiya ${ }^{2}$, Takayuki Ebata ${ }^{2} *$

${ }^{1}$ CNRS, Aix Marseille Université, Physique des Interactions Ioniques et Moleculaires (PIIM) UMR 7345, 13397 Marseille cedex, France

${ }^{2}$ Department of Chemistry, Graduate School of Science, Hiroshima University, Higashi-Hiroshima 739-8526, Japan

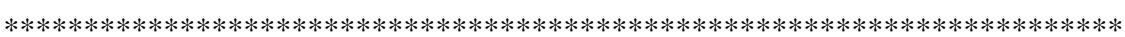

Reprinted with permission from J. Phys. Chem. Lett., 2014, 5 (7), pp 1236-1240.

Copyright 12014 American Chemical Society 
Abstract: A new ultraviolet-ultraviolet hole-burning (UV-UV HB) spectroscopic scheme has been developed for cold gas phase ions in a quadrupole-ion-trap (QIT) connected with a time-of-flight (TOF) mass spectrometer. In this method, a pump UV laser generates a population hole for the ions trapped in the cold QIT and a second UV laser (probe) monitors the population hole for the ions extracted to the field free region of the TOF mass spectrometer. Here, the neutral fragments generated by the UV dissociation of the ions with the second laser are detected. This UV-UV HB spectroscopy was applied to protonated dibenzylamine and to protonated uracil. Protonated uracil exhibits two strong electronic transitions; one has a band origin at $31760 \mathrm{~cm}^{-1}$ and the other at $39000 \mathrm{~cm}^{-1}$. From the UV-UV HB measurement and quantum chemical calculations, the lower energy transition is assigned to the enol-keto tautomer and the higher energy one to the enol-enol tautomer.

\section{Table of contents:}

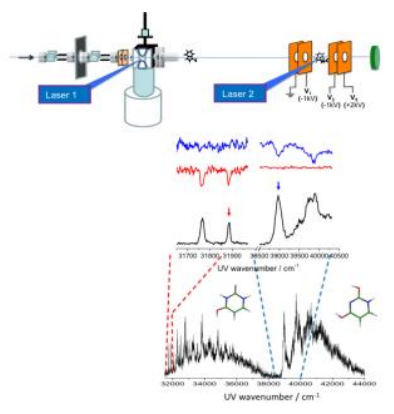

\section{Keywords:}

gas phase cold ion, ion traps, conformers, uracil, electronic spectroscopy 
There has been a great progress in the spectroscopy and characterization of cold gas phase molecular ions and protonated species. ${ }^{1-22}$ The ions are generated by electrospray ionization (ESI), mass-selected and introduced to an ion-trap, such as 22-pole or quadrupole-ion-trap (QIT), cooled to a few tens of K by a cryogenic cooler. Tunable ultraviolet (UV) or infrared (IR) laser light is sent to the trap to photodissociate the ions. By scanning the laser frequency while monitoring the fragment ions, one obtains the IR photodissociation (IRPD) $)^{1-17}$ or UV photodissociation (UVPD) ${ }^{18-22}$ spectrum of the mass-selected ions. In these measurements, we often encounter the problem of the presence of multiple conformers or isomers. Up to now, several spectroscopic methods have been developed to discriminate these species and obtain a conformer or isomer specific spectrum. Rizzo and coworkers applied IR-UV double resonance (DR) scheme to obtain the conformer specific IR spectra of protonated polypeptides ${ }^{10-14}$ and alkali metal cations $\left[\mathrm{M}^{+}\right]$:crown ether complexes. ${ }^{15-17}$ In their setup, UV and IR lasers are collinearly overlapped with the ions in a cold 22-pole trap and the depopulation caused by the IR pump laser is monitored as the depletion in the UVPD signal. Johnson and coworkers reported IR-IR DR spectroscopy for $\mathrm{D}_{2}$-tagged protonated polypeptides. ${ }^{7}$ In their method, the $\mathrm{D}_{2}$-tagged parent ions extracted from the cold QIT are first dissociated by the pump IR laser light. An additional TOF mass-selection stage with mass gate is used to monitor the population hole induced by the pump laser in the ion packet. In this case, a depletion of the parent ions is monitored as a dip in the IRPD ion signals monitored by a probe IR laser.

UV-UV hole-burning (HB) spectroscopy is used to discriminate conformers having different electronic transition frequencies. Very recently, Choi et al. reported UV-UV HB spectroscopy to discriminate conformational isomers of alkali metal cations $\left[\mathrm{M}^{+}\right]$:dibenzo-crown ether complexes and of alkali metal cations $\left[\mathrm{M}^{+}\right]$:benzo-18-crown- $6 .^{22,23}$ In their study, they observed an ejection of fragment ions, which were called escaping ions, immediately after irradiation of the ions in the cold QIT with a UV laser . The escaping ions were used as a probe of a specific parent ion. Under these conditions, an irradiation of a UV pump laser to the QIT prior to the probe laser induced a reduction of the ion signal monitored by the probe UV laser. Thus, the UV-UV HB spectrum is obtained by scanning the probe laser frequency while monitoring the escaping ions. Choi et al. further investigated the mechanism leading to escaping ions, and found that the radio-frequency (rf)-field inside the trap is a critical 
factor for the ejection of the fragment ions and the ion ejection occurs only when its mass to charge ratio is smaller than some lower mass limit. ${ }^{24}$

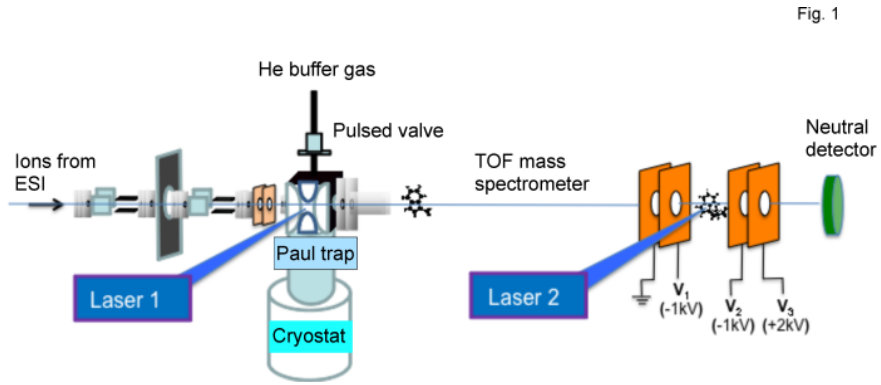

In the present study, we report a new scheme for UV-UV HB spectroscopy applicable to the cold gas phase ions. The key point in this spectroscopy is the detection of neutral fragments produced by UVPD instead of detecting ionic fragments escaping from the trap. ${ }^{22-24}$ As a consequence, there is no constraint on the rf field nor on the mass of the fragments. Figure 1 shows a schematic view of the setup of the present UV-UV HB spectroscopy. The setup consists of an ESI source, a cold quadrupole-ion-trap (QIT), a time-of-flight (TOF) mass spectrometer and two tunable UV pulsed lasers: Laser 1 (L1) and Laser 2 (L2). In the TOF tube, two pairs of grids are placed in front of the microchannel plates (MCP). The ion packet extracted from the trap is accelerated between the first and the second grid. The region between the second and third grids is field free and the probe laser (L2) interacts with the ions in this region to produce neutral and ionic fragments. The final grid, biased at $\mathrm{V}_{3}=+2 \mathrm{kV}$, repels all the ions and only the neutral fragments can reach the MCP detector. In this study, we first show that the spectrum recorded by detecting the neutral fragments produced by UVPD of the ion packet in the TOF tube (one color with L2) is identical to the spectrum obtained by detecting the ion fragments produced by UVPD of the ions in QIT (one color with L1). Here we chose cold protonated dibenzylamine $\left(\left(\mathrm{C}_{6} \mathrm{H}_{5} \mathrm{CH}_{2}\right)_{2} \mathrm{NH}_{2}{ }^{+}\right.$that we abbreviate to $\left.[\mathrm{dBAM}] \mathrm{H}^{+}\right)$. We then show that the combination of the depletion of parent ions by $\mathrm{L} 1$ (pump UV laser) in QIT and probing neutral fragments by L2 decomposition of the ions in the TOF tube provides a new UV-UV HB spectroscopic scheme. This spectroscopy does not have any limits in the detection mass. We applied this spectroscopy to protonated uracil, RNA base. Nucleic-acid bases are susceptible to protonation through proton transfer or other reaction mechanisms, ${ }^{25,26}$ which may produce alternative 
tautomeric structures of the DNA/RNA bases inhibiting the stabilization of base pair structures. Thus, the investigation of the proton acceptor ability of the carbonyl oxygen of the nucleobase is of special importance. It has been recently shown ${ }^{27}$ that protonated uracil exhibits two major UV electronic transitions, one having a band origin at 31760 $\mathrm{cm}^{-1}$ and the other at $39000 \mathrm{~cm}^{-1}$. The two band systems can be due either different electronic states of the same species or to different tautomers. With the UV-UV HB measurement and quantum chemical calculations, we show that the transitions are due to different tautomers, namely the enol-keto and enol-enol forms.

The first question to address is to know whether the ions extracted from the trap are not heated too strongly by collision with $\mathrm{He}$ in the acceleration process. The ions are trapped and cooled down due to pulsed injection of He buffer gas in QIT as seen in refs. 6-9. If the He pressure in the trap is still high at the extraction time $(60 \mathrm{~ms})$ the ions will be collisionally heated. The $[\mathrm{dBAM}] \mathrm{H}^{+}$has low vibrational modes in the ground state (4 modes below $70 \mathrm{~cm}^{-1}$ ), and thus the spectrum should be very sensitive to the collisional heating.

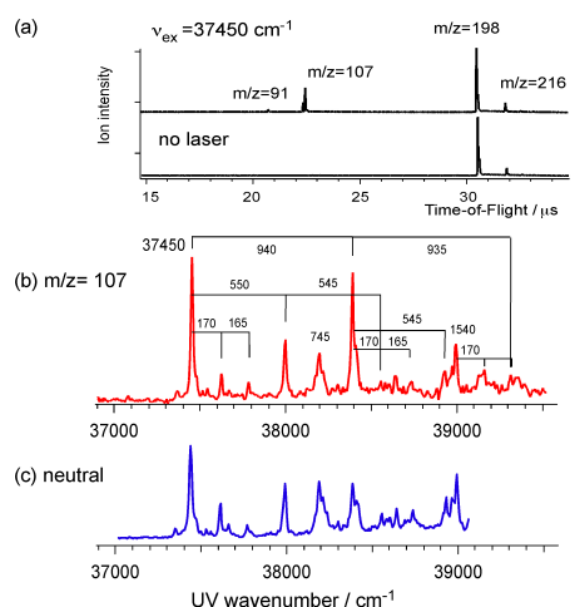

Figure 2(a) shows the TOF mass spectra of $[\mathrm{dBAM}] \mathrm{H}^{+}$in the cold QIT recorded without and with UV irradiation (one color with L1). In this measurement, all the grids inserted in the TOF tube (see Figure 1) are grounded. Without the UV irradiation, two mass peaks are observed: a strong peak at $\mathrm{m} / \mathrm{z}=198\left([\mathrm{dBAM}] \mathrm{H}^{+}\right)$and a weak one at $\mathrm{m} / \mathrm{z}=216$ corresponding to $[\mathrm{dBAM}] \mathrm{H}^{+}-\mathrm{H}_{2} \mathrm{O}$. Irradiation of $\mathrm{L} 1$ to the $[\mathrm{dBAM}] \mathrm{H}^{+}$ions induces production of two ionic fragments at $\mathrm{m} / \mathrm{z}=91$ and 107 , which are assigned to 
$\mathrm{C}_{6} \mathrm{H}_{5} \mathrm{CH}_{2}{ }^{-+}$radical cation and $\mathrm{C}_{6} \mathrm{H}_{5} \mathrm{CH}_{2} \mathrm{NH}_{2}{ }^{+}$cation, respectively. Figure 2(b) shows the UVPD spectrum of $[\mathrm{dBAM}] \mathrm{H}^{+}$(one color with $\mathrm{L} 1$ ) obtained by monitoring the $\mathrm{m} / \mathrm{z}=$ 107 fragment. The spectrum shows a strong band origin at $37450 \mathrm{~cm}^{-1}$ and several vibronic bands involving vibrations of 170 (torsional mode), 550 (mode 12), 745 (mode 6), 930 (mode 1), and $1540 \mathrm{~cm}^{-1}$ of benzyl group, where the notation for the vibrational modes is adapted from Varsanyi. ${ }^{28}$ Figure 2(c) shows the spectrum obtained by monitoring neutral fragments with UV dissociation of the $[\mathrm{dBAM}] \mathrm{H}^{+}$ions in the TOF tube (one color with L2). By comparing the spectra of Figs. 2(b) and 2(c), we see that the neutral fragment detected UV spectrum is almost the same as the ion fragment detected UVPD spectrum (the difference in the signal intensity of the neutral fragment detected spectrum at higher energy, which is larger than that of the $\mathrm{m} / \mathrm{z}=107$ ion detection, is attributed to subsequent fragmentation of the $\mathrm{m} / \mathrm{z}=107$ ion to the $\mathrm{m} / \mathrm{z}=91$ ion at higher energy). Thus, it is confirmed that the extracted ions are still internally very cold. Finally, the UVPD spectrum with the total fragment ion detection shows almost the same intensity pattern with that of the neutral fragment detection. This part is discussed in the supporting information.

Thus, we confirmed that the neutral fragment detected UVPD spectrum in the TOF tube is identical to that of the ion fragment detected UVPD in QIT. We then apply this method to measure UV-UV HB spectrum of gas phase cold ions by using the two lasers. We introduce the pump laser L1 into the cold QIT and the probe laser L2 to the interaction zone of the TOF tube. In this experiment, we choose protonated uracil to demonstrate an ability of the present UV-UV HB spectroscopy in discriminating different isomers or conformers. As described above, protonated uracil has two possible stable tautomers, the enol-enol form and the enol-keto form. Figure 3(a) shows the UVPD spectrum of protonated uracil, which was obtained by measuring the ionic fragment with $\mathrm{m} / \mathrm{z}=70$ (loss of $\mathrm{HNCO}$ ) generated by the photodissociation of protonated uracil trapped in cold QIT. ${ }^{27}$ 


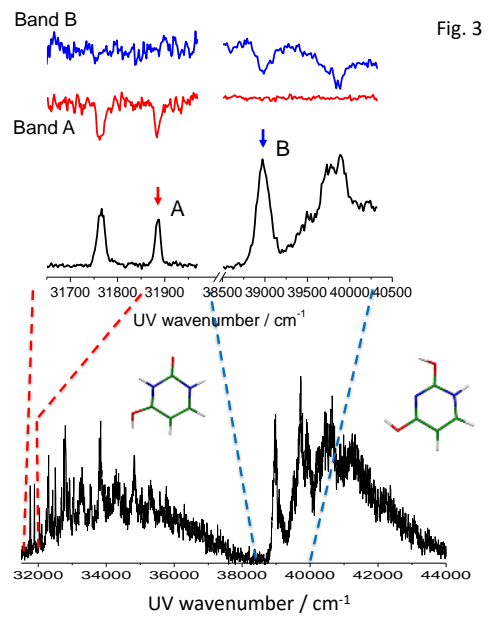

As seen in Fig. 3(a), protonated uracil exhibits two band systems, one starting at $31760 \mathrm{~cm}^{-1}(3.90 \mathrm{eV})$ and the other starting at $39000 \mathrm{~cm}^{-1}(4.83 \mathrm{eV})$. The lower energy band system shows sharp vibronic bands whereas the higher energy one shows rather broad vibronic bands. The two band systems can be assigned either to two different electronic transitions of the same species or to the electronic transitions of two different isomers. To solve the problem, we measure the UV-UV HB spectra by fixing the probe laser L2 to one band of the lower energy system (band A) and to the first broad band of the higher energy system (band B), as shown in Figure 3 (c). When L2 is fixed to band A (red spectra), dips are observed in the lower energy band system but no dip appears in the higher energy band system. On the other hand, when L2 is fixed to band B (blue spectra), dips are observed only in the higher energy band system, but no dip in the lower energy band system. Thus, it is concluded that the two electronic transitions correspond to two different species, and possible candidates are two tautomeric structures. Protonated uracil can form either an enol-keto form or an enol-enol form. It has been reported that the enol-enol form is $0.08 \mathrm{eV}$ more stable than enol-keto in $\mathrm{S}_{0}$ by $a b$ initio calculation at MP2 (Møller-Plesset second order perturbation theory) level. ${ }^{27}$ In addition, excited state $a b$ initio calculations at the RI-ADC(2) level with a correlation-consistent polarized valence double-zeta (cc-pVDZ) basis set predict the $\mathrm{S}_{1} \leftarrow \mathrm{S}_{0}$ transition energy of the enol-keto form at $3.85 \mathrm{eV}$ (optimized in Cs symmetry) and that of the enol-enol form at $5.00 \mathrm{eV}$ (optimized in $\mathrm{Cs}$ symmetry). Thus, the lower 
energy band system $(3.90 \mathrm{eV})$ can be assigned to enol-keto tautomer and the higher energy band system $(4.83 \mathrm{eV})$ to enol-enol tautomer. The presence of the two tautomers of protonated uracil was also reported by QIT/IRPD spectroscopic method by Salpin et al. ${ }^{25}$ and the present study revealed that they exhibit electronic transitions at different regions.

In conclusion, we presented a new scheme of UV-UV HB spectroscopy for cold gas phase ions trapped in QIT. Here, the population hole of the ions generated by the pump laser in QIT is monitored with the probe laser as a depletion of the ions extracted to the TOF tube. Detecting neutral fragments instead of ions with the probe laser makes this spectroscopy unique and simple to apply, without constraints regarding the mass of the photofragments. This technique has allowed the discrimination between the enol-keto and enol-enol tautomers of protonated uracil, RNA base.

\section{EXPERIMENTAL METHODS}

The experimental setup has been described in previous papers ${ }^{18,19}$ The setup is composed of 3 parts: an electrospray ion source (ESI), cold quadrupole-ion-trap (QIT) and a time-of-flight mass spectrometer (TOF-Mass). ${ }^{29,30}$ The protonated ions are produced in the ESI source. ${ }^{31}$ At the exit of the capillary, ions are trapped in an octapole trap for $90 \mathrm{~ms}$. They are extracted by applying a negative pulse and are further accelerated by a second pulsed voltage just after the exit electrode. This time sequence produces ion packets with $500 \mathrm{~ns}-1 \mu$ s duration. The ions are driven by a couple of electrostatic lenses toward the Paul trap biased at $190 \mathrm{~V}$. A mass gate at the entrance of the trap allows selecting the parent ion. The ions are trapped in the Paul trap cooled by a cryostat (Coolpak Oerlikon) and filled with helium buffer gas injected with a pulsed valve. The ions are thermalized at a temperature around $30 \mathrm{~K}$ while they stay in the trap. After $60 \mathrm{~ms}$, the pump UV laser is triggered to dissociate the cold ions. After $30 \mathrm{~ms}$, the fragments and remaining parent ions are extracted to the TOF spectrometer and are detected on a microchannel plates detector (MCP). In the present experiment, the TOF mass spectrometer has been modified to detect neutral particles generated by photodissociation of the parent ions with a probe laser. Neutral particles can be efficiently detected by a MCP detector if their kinetic energy is large enough (a few 
$\mathrm{keV}) .{ }^{32-34}$ Two pairs of grids are placed in front of the MCP. The first grid accelerates the ion packet, and the region between the second and third grids is a field free where the probe laser dissociates the parent ions giving neutral and ionic fragments. The last grid is biased at $\mathrm{V}_{3}=+2 \mathrm{kV}$ and repels all the ions and only the neutral fragments can reach the MCP. The delay time between the probe laser and the extraction voltage from the ion-trap is adjusted to selectively probe the parent ions. The one-color spectrum of neutral photofragment is obtained by scanning the probe laser frequency and recording the neutral fragments on the MCP detector. The UV-UV HB spectrum is obtained by scanning the pump laser frequency, which fragments the parent ions in the trap, while monitoring the neutral fragments with the probe laser held at a fixed frequency. The two lasers are OPO lasers (EKSPLA model-NT342B), which operate at $10 \mathrm{~Hz}$ repetition rate with a scanning step of $0.1 \mathrm{~nm}$. Their spectral resolutions are $8 \mathrm{~cm}^{-1}$. The lasers are shaped to a $2 \mathrm{~mm}^{2}$ spot in the trap or the interaction zone, corresponding to the power of $5 \mathrm{~mW}$.

\section{CALCULATION}

Possible conformers were first searched by AMBER force field calculation and the structures obtained were optimized by $a b$ initio calculations with the TURBOMOLE program package, ${ }^{35}$ making use of the resolution-of-the-identity (RI) approximation for the evaluation of the electron-repulsion integrals. ${ }^{36}$ The equilibrium geometry in $\mathrm{S}_{0}$ was determined at the MP2 level of theory. Vertical excitation energies to the lowest excited singlet states were determined at the RI-ADC(2) (second order Algebraic Diagrammatic Construction) level for protonated uracil. Calculations were performed with the cc-pVDZ basis set or def2-TZVP for the ground state energies.

\section{AUTHOR INFORMATION}

\section{Corresponding Authors}

*E-mail : christophe.jouvet@ univ-amu.fr, tebata@ hiroshima-u.ac.jp

\section{ACKNOWLEDGMENTS}

This study was supported in part by the France-Japan Collaboration Program (SAKURA) France, the Japan Society for Promotion of Science and the ANR Research Grant (ESPEM- ANR2010BLANC040501). We acknowledge the use of the computing

Mis en forme : Français (France) Code de champ modifié Mis en forme : Français (France) Mis en forme : Français (France) 
facility cluster GMPCS of the LUMAT federation (FR LUMAT 2764). Stéphane Coussan and Gaël Roussin are thanked for their help in setting up the experiment.

\section{Supporting Information Available.}

S.1 Water complex of $[\mathrm{dBAM}] \mathrm{H}^{+}$

S.2 Comparison of the ion detected UVPD and neutral fragment detected UVPD spectra of $[\mathrm{dBAM}] \mathrm{H}^{+}$

This information is available free of charge via the Internet at http://pubs.acs.org/ 


\section{References}

1. Polfer, N. C.; Oomens, J. Vibrational Spectroscopy of Bare and Solvated Ionic Complexes of Biological Relevance. Mass Spectrom. Rev. 2009, 28, 468-494

2. Yang, B.; Wu, R. R.; Berden, G.; Oomens, J.; Rodgers, M. T. Infrared Multiple Photon Dissociation Action Spectroscopy of Proton-Bound Dimers of Cytosine and Modified Cytosines: Effects of Modifications on Gas-Phase Conformations. J. Phys. Chem. B 2013, 117,14191-14201

3. Jaeqx, S.; Du, W. ; Meijer, E. J.; Oomens, J. Rijs, A.M. Conformational Study of $\mathrm{Z}-\mathrm{Glu}-\mathrm{OH}$ and Z-Arg-OH: Dispersion Interactions versus Conventional Hydrogen Bonding. J. Phys. Chem. A 2013, 117,1216-1227

4. Citir, M.; Hinton, C. S.; Oomens, J.; Steill, J.D.; Armentrout, P. B. Infrared Multiple Photon Dissociation Spectroscopy of Protonated Histidine and 4-Phenyl Imidazole. Int. J. Mass Spectrom. 2012, 330, 6-15

5. Almasian, M.; Grzetic, J.; van Maurik, J.; Steill, J. D.; Berden, G.; Ingemann, S.; Buma, W. J.; Oomens, Jos. Non-Equilibrium Isomer Distribution of the Gas-Phase Photoactive Yellow Protein Chromophore. J. Phys. Chem. Lett. 2012, 3, 2259-2263

6. Johnson, C. J.; Johnson, M. A. Vibrational Spectra and Fragmentation Pathways of Size-Selected, $\mathrm{D}_{2}$-Tagged Ammonium/Methylammonium Bisulfate Clusters. $J$. Phys. Chem. A 2013, 117, 13265-13274

7. Leavitt, C. M.; Wolk, Arron B.; Fournier, J. A.;Kamrath, Michael Z.; Garand, E.; Van Stipdonk, M. J.; Johnson, M. A. Isomer-Specific IR-IR Double. Resonance Spectroscopy of $\mathrm{D}_{2}$-Tagged Protonated Dipeptides Prepared in a Cryogenic Ion-trap. J. Phys. Chem. Lett. 2012, 3, 1099-1105

8. Garand, E.; Kamrath, M. Z.; Jordan, P. A. ; Wolk, A. B.; Leavitt, C.M.; McCoy, A. B.; Miller, S. J.; Johnson, M. A. Determination of Noncovalent Docking by Infrared Spectroscopy of Cold Gas-Phase Complexes. Science 2012, 335, 694-698

9. Kamrath, M. Z.; Garand, E.; Jordan, P.; Leavitt, C. M.; Wolk, A. B.; Van Stipdonk, M. J.; Miller, S. J.; Johnson, M. A. Vibrational Characterization of Simple Peptides Using Cryogenic Infrared Photodissociation of $\mathrm{H}_{2}$-Tagged Mass-Selected Ions. J. Am. Chem. Soc. 2011, 133, 6440-6448

10. Nagornova, N. S.; Rizzo, T. R.; Boyarkin, O. V. Exploring the Mechanism of IR-UV Double-Resonance for Quantitative Spectroscopy of Protonated Polypeptides and Proteins. Angew. Chemie Int. Ed. 2013, 52, 6002-6005 
11. Lorenz, U. J.; Rizzo, T. R. Multiple Isomers and Protonation Sites of the Phenylalanine/Serine Dimer. J. Am. Chem. Soc. 2012,134, 11053-11055

12. Wassermann, T. N.; Boyarkin, O. V.; Paizs, B.; Rizzo, T. R. Conformation-Specific Spectroscopy of Peptide Fragment Ions in a Low-Temperature Ion-Trap. J. Am. Soc. Mass Spectrom. 2012, 23, 1029-1045

13. Nagornova, N. S.; Rizzo, T. R.; Boyarkin, O. V. Interplay of Intra- and Intermolecular H-Bonding in a Progressively Solvated Macrocyclic Peptide. Science 2012, 336, 320-323

14. Nagornova, N. S.; Rizzo, T. R.; Boyarkin, O. V. Highly Resolved Spectra of Gas-Phase Gramicidin S: A Benchmark for Peptide Structure Calculations, J. Am. Chem. Soc. 2010, 132, 4040

15. Inokuchi, Y.; Kusaka, R.; Ebata, T.; Boyarkin, O. V.; Rizzo, T.R. Laser Spectroscopic Study of Cold Host-Guest Complexes of Crown Ethers in the Gas Phase. ChemPhysChem 2013, 4, 649-660

16. Inokuchi, Y.; Boyarkin, O. V.; Kusaka, R.; Haino, T.; Ebata, T.; Rizzo, T. R. Ion Selectivity of Crown Ethers Investigated by UV and IR Spectroscopy in a Cold Ion-trap. J. Phys. Chem. A 2012, 116, 4057-4068

17. Inokuchi, Y.; Boyarkin, O. V.; Kusaka, R.; Haino, T.; Ebata, T.; Rizzo, T. R. UV and IR Spectroscopic Studies of Cold Alkali Metal Ion-Crown Ether Complexes in the Gas Phase. J. Am. Chem. Soc. 2011, 133, 12256-12263

18. Alata, I. ; Bert, J.; Broquier, M.; Dedonder, C. ; Feraud, G.; Gregoire, G.; Soorkia, S.; Marceca, E.; Jouvet, C. Electronic Spectra of the Protonated Indole Chromophore in the Gas Phase. J. Phys. Chem. A 2013, 117, 4420-4427

19. Féraud, G. ; Broquier, M. ; Dedonder-Lardeux, Claude. ; Grégoire, G. ; Soorkia, S. ; Jouvet, C. Photofragmentation Spectroscopy of Cold Protonated Aromatic Amines in the Gas Phase. Phys. Chem. Chem. Phys. 2014, Advance Article. DOI $10.1039 / \mathrm{c} 3 \mathrm{cp} 54736 \mathrm{a}$.

20. Feraud G.; Dedonder, C.; Soorkia, S. ; Jouvet, C. Photo-Fragmentation Spectroscopy of Bezylium and 1-Phenylethyl Cations. J. Chem. Phys. 2014, 140, 024302 (10 pages)

21. Choi, C. M.; Kim, H. J.; Lee, J. H.; Shin, W. J.; Yoon, T. O.; Kim N. J.; Heo, J. Ultraviolet Photodepletion Spectroscopy of Dibenzo-18-Crown-6-Ether Complexes with Alkali Metal Cations. J. Phys. Chem. A 2009, 113, 8343-8350

22. Choi, C. M.; Choi, D. H.; Heo, J.; Kim N. J.; Kim S. K. Ultraviolet-Ultraviolet Hole 
Burning Spectroscopy in Quadrupole Ion Trap: Dibenzo[18]Crown-6 Complexes with Alkali Metal Cations. Angew. Chemie Int. Ed. 2012, 51, 7297-7300

23. Choi, C. M.; Baek, J. Y.; Park, K. S.; Heo, J. ; Kim N. J. Conformation-Specific Ultraviolet Spectroscopy of Benzo-18-Crown-6 Complexes with a Potassium Cation. Chem. Phys. Lett. 2014, 593, 150-153

24. Choi, C. M.; Heo, J.; Choi, M. C.; Kim N. J. Ejection Process of Photofragment Ions from a Quadrupole Ion Trap. Int. J. Mass Spectrom. 2013, 337, 12-17

25. Salpin, J-Y.; Guillaumont, S.; Tortajada, J.; MacAleese, L.; Lemaire, J.; Matire, P. Infrared Spectra of Protonated Uracil, Thymine, and Cytosine. ChemPhysChem 2007, 8, 2235-2244

26. Tuna, D.; Sobolewski, A. L.; Domcke, W. Mechanisms of Ultrafast Excited-State Deactivation in Adenosine. J. Phys. Chem. A 2014, 118, 122-127.

27. Berdakin, M.; Féraud, G.; Dedonder-Lardeux, C.; Jouvet, C. ; Pino, G. A. Excited States of Protonated DNA/RNA bases. Phys. Chem. Chem. Phys. in press.

28. Varsanyi, G. Assignments for Vibrational Spectra of Seven Hundreds Benzene Derivatives; Adam Hilger, London; 1974.

29. Wang, X. B.; Wang, L. S. Development of a Low-Temperature Photoelectron Spectroscopy Instrument Using an Electrospray Ion Source and a Cryogenically Controlled Ion-Trap. Rev. Sci. Instrum. 2008, 79, 073108

30. Choi, C. M.; Choi, D. H.; Kim, N. J.; Heo, J. Effective Temperature of Protonated Tyrosine Ions in a Cold Quadrupole Ion-Trap. Int. J. Mass Spectrom. 2012, 314, $18-21$

31. Andersen, J. U.; Hvelplund, P.; Nielsen, S. B.; Tomita, S.; Wahlgreen, H.; Møller, S. P.; Pedersen, U. V.; Forster, J. S.; Jørgensen, T. J. D. The Combination of an Electrospray Ion Source and an Electrostatic Storage Ring for Lifetime and Spectroscopy Experiments on Biomolecules. Rev. Sci. Instrum. 2002, 73, 12841287

32. Barat, M.; Brenot, J. C.; Fayeton, J. A. ; Picard, Y. J. Absolute Detection Efficiency of a Microchannel Plate Detector for Neutral Atoms. Rev. Sci. Instrum. 2000, 71, $2050-2052$.

33. Lepère, V.; Lucas, B. ; Barat, M. ; Fayeton, J. A. ; Picard, Y. J.; Jouvet, C.; Çarçabal, P.; Nielsen, I. ; Dedonder-Lardeux, C.; Grégoire, G. ; Fujii , A. Characterization of 
Neutral Fragments Issued from the Photodissociation of Protonated Tryptophane. Phys. Chem. Chem. Phys. 2007, 9,5330-5334.

34. Alata, I.; Dedonder, C.; Broquier, M.; Marceca, E.; Jouvet, C. Role of the Charge-Transfer State in the Electronic Absorption of Protonated Hydrocarbon Molecules. J. Am. Chem. Soc. 2010, 132,17483-17489.

35. Ahlrichs, R.; Bär, M.; Häser, M.; Horn, H.; Kölmel, C. Electronic Structure Calculation on Workstation Computers: The Program System Turbomole. Chem. Phys. Lett., 1989, 162, 165-169.

36. Hattig, C. Geometry Optimizations with the Coupled-Cluster Model CC2 using the Resolution-of-the-Identity Approximation. J. Chem. Phys. 2003, 118, 7751-7761.

\section{Figure caption}

Figure 1 Experimental setup for UV-UV HB spectroscopy with neutral fragment detection.

Figure 2 (a) Time-of-Flight spectrum of protonated dibenzylamine $\left([\mathrm{dBAM}] \mathrm{H}^{+}\right)$with and without a irradiation of UV laser light to the cold QIT. (b) UVPD spectrum of $[\mathrm{dBAM}] \mathrm{H}^{+}$in the cold QIT with detection of the $\mathrm{m} / \mathrm{z}=107$ ion fragments. (c) UVPD spectrum of $[\mathrm{dBAM}] \mathrm{H}^{+}$with detection of neutral fragments, where the UV laser, L2, dissociates the ions in the TOF tube (See Fig. 1).

Figure 3 (a) UVPD spectrum of protonated uracil in the cold QIT showing two transitions. (b) Expanded scale of the UVPD spectrum showing the first bands of the two transitions. (c) UV-UV HB spectra of protonated uracil measured by fixing the UV frequency to bands A (red) and B (blue), respectively, of the UVPD spectrum. 


\section{Supporting Information}

\section{Development of Ultraviolet-Ultraviolet Hole-burning Spectroscopy for}

\section{Cold Gas Phase Ions}

Géraldine Féraud ${ }^{1}$, Claude Dedonder ${ }^{1}$, Christophe Jouvet ${ }^{1 *}$, Yoshiya Inokuchi ${ }^{2}$, Takeharu Haino $^{2}$, Ryo Sekiya ${ }^{2}$, Takayuki Ebata ${ }^{2 *}$

${ }^{1}$ CNRS, Aix Marseille Université, Physique des Interactions Ioniques et Moleculaires (PIIM) UMR 7345, 13397 Marseille cedex, France

${ }^{2}$ Department of Chemistry, Graduate School of Science, Hiroshima University, Higashi-Hiroshima 739-8526, Japan

\section{S1. Water Complex of [dBAM] ${ }^{+}$}

In Figure 2(a), [dBAM] $\mathrm{H}^{+}-\mathrm{H}_{2} \mathrm{O}$ complex is formed in QIT during the cooling process. $\mathrm{UV}$ excitation of this complex in the trap only gives $[\mathrm{dBAM}] \mathrm{H}^{+}$as fragment, so that its UVPD spectrum cannot be obtained. Instead, the photodissociation spectrum of this complex can be recorded with the neutral fragment detection scheme by adjusting the delay of laser L2 (one color experiment) so that it interacts with the [dBAM] $\mathrm{H}^{+}-\mathrm{H}_{2} \mathrm{O}$ complex ion in the TOF. The neutral photofragmentation spectrum of the $[\mathrm{dBAM}] \mathrm{H}^{+}-\mathrm{H}_{2} \mathrm{O}$ complex is shown in figure $\mathrm{S} 1$ (a) and that of $[\mathrm{dBAM}] \mathrm{H}^{+}$in figure $\mathrm{S} 1$ (b). The origin of the water complex spectrum is blue-shifted by $90 \mathrm{~cm}^{-1}$ with respect to that of free $[\mathrm{dBAM}] \mathrm{H}^{+}$.

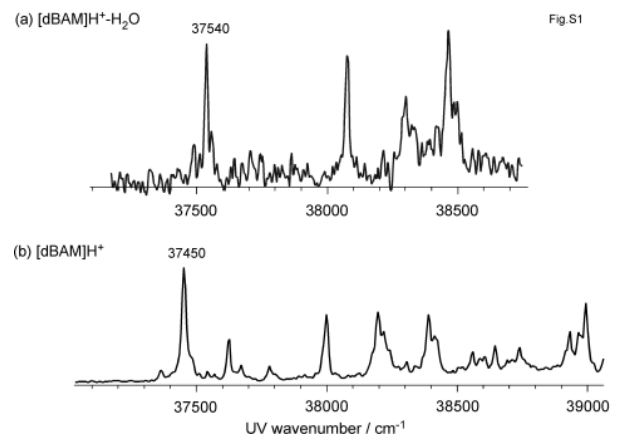

Figure S1. UV photofragment spectra of (a) $[\mathrm{dBAM}] \mathrm{H}^{+}-\mathrm{H}_{2} \mathrm{O}$ and (b) $[\mathrm{dBAM}] \mathrm{H}^{+}$. Here, neutral fragments are detected in both spectra. 


\section{S2.Comparison of ion detected UVPD and neutral fragment detected UVPD spectra of [ABAM] $\mathrm{H}^{+}$}

Figure $\mathrm{S} 2$ shows a comparison of the UVPD spectrum of $[\mathrm{dBAM}] \mathrm{H}^{+}$between the ion fragment detection and neutral fragment detection. In figures S2 (a) and (b), a tunable UV laser light, L1 in Fig. 1, is interacting with the ions in the cold QIT, and the ion fragments $\mathrm{m} / \mathrm{z}=91$ and 107 are detected as a function of the laser wavenumber. Figure S2 (c) shows the UVPD spectrum when all the fragment ions are detected: this spectrum is obtained in adding the spectra of figure S2 (a) and S2 (b). Figure S2 (d) shows the neutral fragment detected UVPD spectrum of $[\mathrm{dBAM}] \mathrm{H}^{+}$, where a tunable UV laser light, L2 in Fig. 1, dissociates the ions in the TOF tube. Figures S2 (c) and (d) are similar, showing that neutral fragment detected UVPD spectrum in the TOF tube is equivalent to the ion fragment detected UVPD spectrum in QIT.

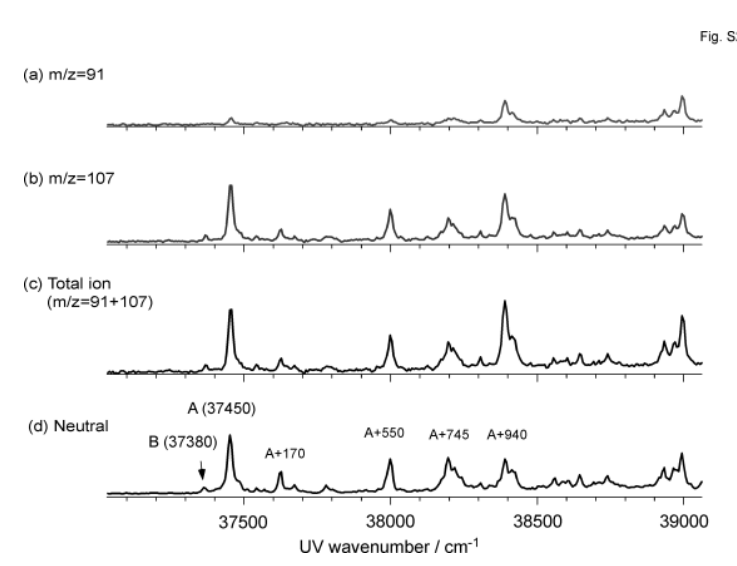

Figure S2. UVPD spectra of $[\mathrm{dBAM}] \mathrm{H}^{+}$in the cold QIT with detections of (a) $\mathrm{m} / \mathrm{z}=91$ and (b) $\mathrm{m} / \mathrm{z}=107$ ionic fragments. (c) UVPD spectrum with detection of all the ionic fragments (sum of the spectra recorded on the $m / z=91$ and 107 fragments). (d)UVPD spectrum of $[\mathrm{dBAM}] \mathrm{H}^{+}$with a detection of neutral fragments. 